\title{
PENGOLAHAN UBI UNGU DI DESA PULAU BANGKINANG SEBERANG
}

\author{
Apriza $^{1}$, Erlinawati ${ }^{2}$ \\ ${ }^{1}$ Program Studi Profesi Ners, Fakultas Ilmu Kesehatan, Universitas Pahlawan Tuanku Tambusai \\ apriza@universitaspahlawan.ac.id \\ ${ }^{2}$ Program Studi D III Kebidanan, Fakultas Ilmu Kesehatan, Universitas Pahlawan Tuanku Tambusai \\ e-mail : erlinawati@universitaspahlawan.ac.id
}

\begin{abstract}
Abstrak
Desa Pulau merupakan salah satu desa yang berada di Kecamatan Bangkinang Seberang Kabupaten Kampar. Permasalahan yang ditemukan di Desa tersebut adalah; penghasilan kelompok wirid RT02 RW 04 masih rendah, pengetahuan anggota Wirid RT02 RW 04 tentang pengolahan ubi ungu menjadi produk makanan yang bergizi masih rendah atau belum ada, diversifikasi dan pemasaran produk makanan belum ada, P IRT belum ada. Tujuan pengabdian ini adalah untuk mengembangkan olahan ubi ungu menjadi produk olahan makanan untuk meningkatkan pendapatan masyarakat RT02 RW 04 Desa Pulau Bangkinang Seberang. Metode pengabdian yaitu model Community development, model Participatory Rural Appraisal (PRA), sosialisasi, dan metode pendampingan. Pengabdian pengolahan ubi ungu menjadi produk makanan keripik, donat dan bolu dilaksanakan pada tanggal 28 Oktober 2019 s.d 30 Oktober 2019 di desa Pulau Bangkinang Seberang, diikuti oleh 6 orang yang tergabung kedalam kelompok wirid RT 02 dengan hasil ; 1) Antusias mitra terhadap sosialisasi serta pelatihan yang telah dilakukan dalam peningkatan produksi pengolahan ubi ungu berupa variasi produk baru hasil olahan ubi ungu yaitu; keripik ubi ungu, donat dan bolu sebesar $100 \%, 2$ ) Meningkatnya pengetahuan dan keterampilan mitra tentang pengolahan ubi ungu menjadi varian produk lain sebesar $90 \%$, 3) Mitra mampu membuat produk keripik ubi ungu, donat ubi ungu dan bolu ubi ungu sebesar 100\%, 4) Meningkatnya pengetahuan cara packing dari produk dan cara untuk menjual ke masyarakat dengan menggunakan gadget sebesar $90 \%$. Kesimpulan pengabdian meningkatnya pengetahuan dan keterampilan mitra tentang pengolahan ubi ungu menjadi varian produk lain.
\end{abstract}

Kata Kunci: Pengolahan Ubi Ungu, Kelompok Mitra Desa Pulau Bangkinang Seberang

\section{Abstract}

Pulau Village is one of the villages in the District of Bangkinang Seberang, Kampar Regency. Problems found in the village are; wirid RT02 RW 04 group's income is still low, the knowledge of members of Wirid RT02 RW 04 about processing purple sweet potato into nutritious food products is still low or not available, diversification and marketing of food products is not yet available, $P$ IRT does not yet exist. The purpose of this service is to develop processed purple sweet potato into a food processed product to increase the income of RT02 RW 04 in Desa Bangkinang Seberang Village. Service methods are Community development model, Participatory Rural Appraisal (PRA) model, socialization, and mentoring method. The service of processing purple sweet potato into food products, chips, donuts and sponge was carried out on 28 October 2019 to 30 October 2019 in the village of Bangkinang Seberang Island, followed by 6 people who joined the RT 02 wirid group with the results; 1) Enthusiastic partners in the socialization and training that have been carried out in increasing the production of processing of purple sweet potato in the form of variations of new products processed from purple sweet potato, namely; purple sweet potato chips, donuts and sponge by 100\%, 2) Increased knowledge and skills of partners about processing purple sweet potatoes into other product variants by 90\%, 3) Partners are able to make purple 
sweet potato chips, purple sweet potato donuts and purple sweet potato sprouts by $100 \%, 4)$ Increased knowledge of how to pack products and how to sell to the public by using gadgets by 90\%. The conclusion of the dedication of increasing partners' knowledge and skills regarding processing of sweet potatoes is becoming another product variant.

Keywords : Purple Sweet Potato Processing, Bangkinang Seberang Island Village Partner Group

\section{PENDAHULUAN}

Desa Pulau merupakan salah satu desa yang berada di Kecamatan Bangkinang Seberang Kabupaten Kampar. Masyarakat di Kecamatan Bangkinang Seberang memiliki berbagai mata pencaharian yang dipengaruhi oleh lingkungan mereka tinggal. Mata pencaharian yang mendominasi di Bangkinang Seberang adalah sektor pertanian/perkebunan dan perdagangan. Pada umumnya ibu rumah tangga di desa ini banyak yang berdiam diri dirumah. Pemenuhan biaya hidup merupakan tanggung jawab kepala keluarga sepenuhnya. Waktu luang yang banyak tersisa dimanfaatkan ibu-ibu rumah tangga untuk membentuk organisasi sosial yang tergabung dalam wirid pengajian RT 02 RW 04 .

Wirid pengajian RT 02 RW 04 merupakan satu-satunya organisasi sosial yang masih aktif di RT 02 RW 04 desa Pulau Bangkinang Seberang. Wirid pengajian RT ini sudah terbentuk lebih kurang 7 tahun yang lalu. Kegiatan rutin yang dilakukan kelompok ini adalah arisan, wirid pengajian, membantu pelaksanaan pengobatan ringan yang dikoordinir oleh bidan desa. Sedangkan program lain yang pelaksanaannya masih tersendat-sendat yaitu usaha menghasilkan produk makanan yang dapat diperjual belikan ke masyarakat.

Hasil perbincangan tim pengabdi Universitas Pahlawan Tuanku Tambusai dengan kelompok Wirid pengajian RT 02 RW 04 yang diwakili oleh ibu Lina selaku anggota Wirid pengajian RT02 RW 04 menyampaikan bahwa; kegiatan wirid pengajian RT masih sebatas kegiatan rutin yang dilakukan, mengaji, arisan dan mendatangkan ustad/ustazah untuk ceramah. Belum ada kegiatan kegiatan yang bersifat menghasilkan uang untuk peningkatan kesejahteraan anggotanya. Informasi yang didapatkan bahwa, masyarakat desa pulau banyak yang berkecimpung dalam usaha perkebunan tanaman palawija. Hasil palawija hanya dijual kepasar dan kadang kadang dijual kepengepul dengan harga yang minim. Ubi ungu merupakan salah satu tanaman palawija yang tumbuh subur di desa ini. Belum ada ide dari masyarakat untuk mengolah ubi ini untuk menjadi produk makanan yang bergizi dan memiliki daya jual yang tinggi

Hasil analisis dari tim pengabdi Universitas Pahlawan Tuanku Tambusai meyakini kelompok Wirid RT ini bisa lebih bermanfaat lagi dan mampu menjalankan program yang telah disusun jika mereka mempunyai pendapatan tersendiri dari suatu usaha yang bisa dikembangkan dan dipasarkan ke khalayak ramai.

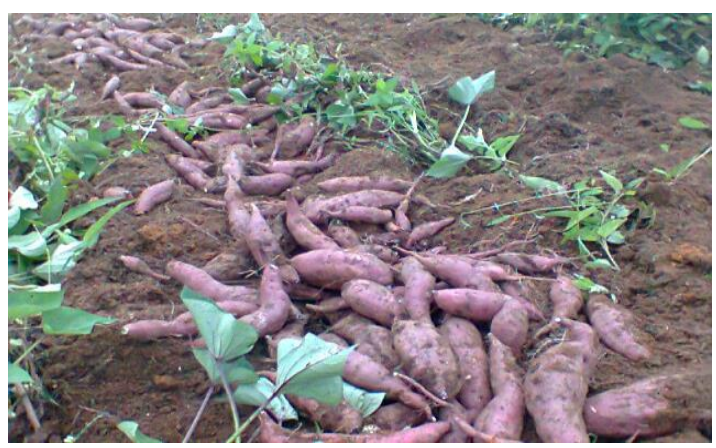

Gambar 1 Ubi Ungu 
Melalui upaya pengabdian masyarakat yang merupakan salah satu dari Tri Dharma Perguruan Tinggi, maka tim pengabdian masyarakat Universitas Pahlawan Tuanku Tambusai sangat berkeinginan untuk memperdayakan kelompok RT02 RW 04 untuk mengolah ubi ungu agar bisa dikembangkan menjadi berbagai produk makanan yang bernilai gizi tinggi.

\section{METODE}

Kegiatan PKM pengolahan ubi ungu menjadi produk makanan keripik, donat dan bolu dilaksanakan pada tanggal 28 Oktober 2019 s.d 30 Oktober 2019 di desa Pulau Bangkinang Seberang, diikuti oleh 6 orang yang tergabung kedalam kelompok wirid RT 02. Pelaksanaan kegiatan PKM Kelompok Wirid RT02 RW 04 Desa Pulau Kecamatan Bangkinang seberang dilakukan melalui beberapa pendekatan yaitu model Community development, Participatory Rural Appraisal (PRA), sosialisasi dan metode pendampingan.

Kegiatan ini dilakukan disalah satu rumah anggota mitra yaitu ibu lina. Kegiatan yang dilakukan yaitu:

1. Sebelum pengolahan ubi ungu menjadi produk kerupuk, donat dan ubi, mitra dibekali dengan penyuluhan/sosialisasi terkait ubi ungu, manfaat dan cara pengolahannya.Dalam kegiatan ini, pengabdi dari tim Universitas Pahlawan Tuanku Tambusai mensosialisasikan cara pengolahan ubi ungu melalui media elektronik menggunakan video. Hal ini dilakukan agar memberikan kesan menarik dan meningkatkan antusias dan motivasi peserta.

2. Setelah itu diberi tim pengabdi mencontohkan cara pengolahan secara langsung dengan melibatkan peserta.

3. Membagi peserta kedalam 2 kelompok dan di tugasi masing masing kelompok untuk membuat olahan yang telah disosialisasikan.

Dalam pelaksanaan kegiatan ini tim pengabdi bersifat sebagai narasumber, fasilitasi dan observasi.

Pelaksanaan kegiatan PKM Kelompok Wirid RT02 RW 04 Desa Pulau Kecamatan

Bangkinang seberangadalah sebagai berikut:

1. Persiapan

Pada tahap persiapan ini dilakukan untuk menginventarisasi kondisi Wirid RT02 RW 04 yang telah menyatakan kesediaan untuk bekerjasama. Diskusi dengan pihak Wirid RT02 RW 04 memilih dan mengelompokkan permasalahan-permasalahan yang harus diselesaikan terlebih dahulu dan menyusun solusi pemecahan masalah. Menginventarisasi kegiatan kegiatan yang akan dilakukan secara berurutan dan dibuat jadwal yang telah disepakati.

2. Pelaksanaan kegiatan

Pelaksanaan kegiatan disepakati dengan mitra dan merujuk kepada waktu pelaksanaan yang telah ditentukan. Introduksi sains, iptek, rekayasa sosial atau lainnya yang akan diterapkan setiap kegiatan yang akan dilakukan.

3. Evaluasi dan monitoring

Evaluasi dan monitoring kegiatan dilakukan secara berkala dan terjadwal dengan melibatkan Ketua RT Pulau. Pelaksanaan evaluasi akan dilakukan setelah kegiatan dilaksanakan untuk melihat pencapaian keberhasilan.

\section{HASIL DAN PEMBAHASAN}

Hasil kegiatan pengabdian masyarakat yang dicapai adalah 1) Antusias mitra terhadap sosialisasi serta pelatihan yang telah dilakukan dalam peningkatan produksi pengolahan ubi ungu berupa variasi produk baru hasil olahan ubi ungu yaitu; keripik ubi ungu, donat dan bolu, 2) Meningkatkan pengetahuan dan keterampilan mitra tentang pengolahan ubi ungu menjadi varian produk lain, 3)Praktik pengolahan ubi ungu menjadi variasi produk baru berupa keripik, donat dan bolu, 4) Mitra mampu membuat produk keripik ubi ungu, donat ubi ungu dan bolu ubi ungu, 5) Diajarkan cara packing dari produk dan cara untuk menjual ke masyarakat dengan menggunakan gadget. 
Pelaksanaan kegiatan PKM Kelompok Wirid RT02 RW 04 Desa Pulau Kecamatan Bangkinang seberang yang dilakukan melalui beberapa pendekatan menyebabkan tercapainya tujuan pengabdian melalui pendekatan yang melibatkan masyarakat secara langsung sebagai subjek dan objek pelaksanaan kegiatan pengabdian kepada masyarakat, kemudia melalui keterlibatan masyarakat secara keseluruhan mulai dari perencanaan, pelaksanaan dan evaluasi kegiatan (Supriatna, 2014). Model pendampingan kelompok Dasawisma dilakukan dengan menerapkan jenis penelitian dan pengembangan atau Research and Development $(R \& D)$, yaitu suatu proses atau langkah-langkah untuk mengembangkan suatu produk baru atau menyempurnakan produk yang telah ada yang dapat dipertanggungjawabkan. Model penelitian dan pengembangan pada tahap implementasi model pendampingan desa ini melalui pendidikan, penyuluhan, pendampingan, pelatihan dan menghasilkan produk berbasis potensi lokal.

\section{SIMPULAN}

1. Meningkatnya pengetahuan dan keterampilan mitra tentang pengolahan ubi ungu menjadi varian produk lain

2. Mitra mampu membuat produk keripik ubi ungu, donat ubi ungu dan bolu ubi ungu

3. Mitra mampu mempacking produk dan memasarkan ke masyarakat dengan menggunakan gadget.

\section{SARAN}

Kepada pengabdi selanjutnya disarankan agar melakukan pembinaan kelopok wirit di Desa lain secara berkelanjutan.

\section{UCAPAN TERIMA KASIH}

Penulis mengucapkan terimaksih kepada Universitas Pahlawan Tuanku Tambusai yuang telah memberikan dukungan finansial kegiatan pengabdian masyarakat ini.

\section{DAFTAR PUSTAKA}

Andarwulan N, Kusnandar F, dan Herawati D. (2011). Analisis Pangan. Dian Ilmu. Jakarta

Koswara, S. (2013). Teknologi Pengolahan Umbi-umbian (Bag. 5 Pengolahan Ubi Jalar). Southeast Asian Food And Agricultural Science and Technology (SEAFAST) Center, Bogor.

Notoatmodjo, S. (2000). Pendidikan dan Perilaku Kesehatan. Jakarta: Rineka Cipta.

Sitoayu, L. (2018). Pemanfaatan Bahan Makanan Sederhana menjadi Gizi Seimbang. Jurnal Abdimas (4)2: 230-234. 